\title{
Regulatory Basis for the Waste Isolation Pilot Plant Performance Assessment
}

\author{
B.A. Howard ${ }^{2}$, M.B. Crawford ${ }^{b}$, D.A.Galson ${ }^{b}$, and M.G. Marietta ${ }^{a}$ \\ 'Sandia National Laboratories, P.O. Box 5800, Albuquerque, NM 87185, USA \\ ${ }^{\mathrm{b}}$ Galson Sciences Limited. 5 Grosienor House, Melton Road, Oakham, Rutland LEI5 6AX. UK

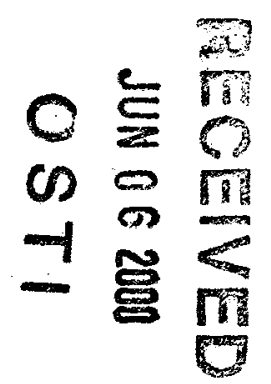

\begin{abstract}
The Waste Isolation Pilot Plant (WIPP) is the first operational repository designed for the safe disposal of transuranic (TRU) radioactive waste from the defense programs of the U.S. Department of Energy (DOE). The U.S. Environmental Protection Agency (EPA) is responsible for certifications and regulation of the WIPP facility for the radioactive components of the waste. The EPA has promulgated general radioactive waste disposal standards at 40 CFR Part 191, and WIPP-specific criteria to implement and interpret the generic disposal standards at 40 CFR Part 194. In October 1996, the DOE submitted its Compliance Certification Application (CCA) to the EPA to demonstrate compliance with the disposal standards at Subparts B and C of 40 CFR Part 191. This paper summarizes the development of the overall legal framework for radioactive waste disposal at the WIPP, the parallel development of the WIPP performance assessment (PA), and how the EPA disposal standards and implementing criteria formed the basis for the CCA WIPP PA. The CCA resulted in a certification in May 1998 by the EPA of the WIPP's compliance with the EPA's disposal standard, thus enabling the WIPP to begin radioactive waste disposal.
\end{abstract}

Key Words: compliance certification application; features, events and processes; performance assessment; transuranic waste; uncertainty: Waste Isolation Pilot Plant; 40 CFR 191; 40 CFR 194.

Please send page proof to:

Bryan Howard

Department 6821, MS 1395

Sandia National Laboratories

115 N. Main St.

Carlsbad. NM 88220, USA

Phone: 505-234-0065

Fax: 505-234-0061

Email: bahowara'sandia.gor 


\section{DISCLAIMER}

This report was prepared as an account of work sponsored by an agency of the United States Government. Neither the United States Government nor any agency thereof, nor any of their employees, make any warranty, express or implied, or assumes any legal liability or responsibility for the accuracy, completeness, or usefulness of any information, apparatus, product, or process disclosed, or represents that its use would not infringe privately owned rights. Reference herein to any specific commercial product, process, or service by trade name, trademark, manufacturer, or otherwise does not necessarily constitute or imply its endorsement, recommendation, or favoring by the United States Government or any agency thereof. The views and opinions of authors expressed herein do not necessarily state or reflect those of the United States Government or any agency thereof. 


\section{DISCLAIMER}

Portions of this document may be illegible in electronic image products. Images are produced from the best available original document. 
The Waste Isolation Pilot Plant (WIPP) is used for the disposal of transuranic (TRU) radioactive waste from defense programs of the U.S. Department of Energy (DOE). The WIPP facility is located 20 miles $(42 \mathrm{~km})$ east of the town of Carlsbad in southeastern New Mexico. The repository is located in the northern Delaware Basin, 2,150 feet (655 meters) underground in the Permian-age Salado bedded salt formation.

The U.S. Environmental Protection Agency (EPA) is responsible for the regulatory oversight of the radioactive waste disposal at the WIPP facility. The EPA's role is defined by the WIPP Land Withdrawal Act (LWA), passed initially by Congress in 1992 and amended in $1996^{1,2}$. Specifically, the LWA delegated three sequential tasks to the EPA. First, the EPA had to finalize general regulations (non-site specific) that it first published in 1985, for highly radioactive waste disposal ${ }^{3}$. The final form was published in the Federal Register in 1993, located at 40 CFR Part 191, and limits the amount of radioactive material that may escape from a disposal facility to the accessible environment, and protects individuals and groundwater resources from radioactive contamination ${ }^{4}$. Second, the EPA had to develop by rulemaking, criteria to implement and interpret the general 40 CFR Part 191 radioactive waste disposal regulations specifically for the WIPP. The EPA issued its "WIPP Compliance Criteria", at 40 CFR Part 194, in $1996^{5}$. These criteria described what information the DOE must submit in order to comply with the disposal standards at Subparts B and C of 40 CFR Part 191a, and clarified the basis on which the EPA's compliance determination will be made. Third, the EPA had to review information submitted by the DOE in response to 40 CFR Parts 191 and 194, and publish a determination of compliance.

In October 1996, the DOE submitted its Compliance Certification Application (CCA) to the EPA to demonstrate compliance with the EPA's radioactive waste disposal standards. In May 1998, after a 19-month review process, the EPA stated in its final certification decision that the WIPP will comply with the EPA's disposal standards?

In accordance with the EPA regulations and criteria, the CCA contained a series of calculations that assessed the performance of the WIPP facility over the next 10,000 years in terms of radioactive releases and human safety. The requirements of the CCA WIPP performance assessment (PA) were prescribed by the EPA regulations and criteria, which specified: (1) the context of the PA within the overall decision-making process; (2) the assessment time periods that the PA should cover; (3) the basis for the treatment of uncertainty; (4) the requirements for peer review; (5) a basis for deciding what should be included and excluded from consideration in the PA and, in some cases, the methodology for how specific features, events, and processes (FEPs) that may potentially impact the performance of

\footnotetext{
a Subpart A of the EPA's 40 CFR Part 191 standards applies to management and storage operations and considers operational safety rather than disposal. It is not implemented for the WIPP by 40 CFR Part 194, and is not considered in this paper.
} 
the repository should be treated; and (6) the requirements for documentation and quality assurance (QA) of the model and software development and verification process, and the methodology and QA requirements for data qualification and parameterization.

This paper summarizes the development of the legal framework for radioactive waste disposal at the WIPP (Sect. 2) and the parallel development of the WIPP PA (Sect. 3). It then describes how the EPA disposal regulations and criteria formed the basis for the CCA WIPP PA (Sect. 4). Companion papers in this volume describe the PA development methodology and the mechanics of the CCA WIPP PA itself.

Only the EPA regulations and criteria that directly affect the PA calculations are considered in this paper. However, the EPA regulations also codify good practice regarding documentation and quality assurance of activities that support or affect the development of PA models and data, such as site characterization, waste characterization, expert judgement, and assurance measures (Fig. $1^{8}$ ). Regulations other than 40 CFR Parts 191 and 194 that apply to WIPP and that have had little or no influence on the evolution of the WIPP PA, are not discussed in this paper.

\section{EVOLUTION OF THE REGULATORY FRAMEWORK FOR THE WIPP}

This section covers the key steps and legal acts that led to the establishment of the EPA as the regulatory authority for radioactive waste disposal at the WIPP, and the development of the EPA's general disposal standards and WIPPspecific criteria at 40 CFR Part 191 and 194, respectively.

Systematic studies of radioactive waste disposal options began in the United States in 1955, when the Atomic Energy Commission (AEC), the predecessor to the DOE, asked the National Academy of Sciences (NAS) to examine the issue. In 1957, the NAS reported that, while various options and disposal sites were feasible, disposal in salt beds was the most promising method ${ }^{9}$. From 1957 through the early 1970s, Oak Ridge National Laboratory (ORNL) conducted research associated with the disposal of radioactive waste in salt, including a large-scale field program in an abandoned salt mine near Lyons, Kansas. However, pre-existing human-induced features in an area near the Lyons mine prompted the AEC to reject the mine as a potential repository site. In 1973, after a nationwide search for a suitable site, ORNL and the United States Geological Survey selected the Delaware Basin in New Mexico as a site that satisfied their selection guidelines. In 1975, after exploratory work, a potential site east of Carlsbad was identified for further site characterization ${ }^{10}$.

The identified site was officially authorized by the U.S. Congress in 1979 through Public Law 96-164, entitled "Department of Energy National Security and Military Applications of Nuclear Energy Authorization Act of 
1980"11. Public Law 96-164 appropriated funds for the WIPP activities and, at Paragraph (a) of Section 213, defined the mission of the WIPP Project as having "... the express purpose of providing a research and development facility to demonstrate the safe disposal of radioactive waste resulting from the defense activities and programs of the United States ...” . Public Law 96-164 also excluded the WIPP from U.S. Nuclear Regulatory Commission (NRC) licensing (Sections 210 and 213), and provided the basis for the Consultation and Cooperation Agreement (C\&C) reached by the DOE and the State of New Mexico in $1981^{12}$. At this time, the DOE was self-regulating.

The 1982 Nuclear Waste Policy Act (NWPA) (Public Law 97-425) first established a role for the EPA with regard to licensing of the WIPP ${ }^{13}$. The role of the EPA (the Administrator) is defined in the NWPA at Section 121(a):

ENVIRONMENTAL PROTECTION AGENCY STANDARDS. - Not later than 1 year after the date of enactment of this Act, the Administrator, pursuant to authority under other provisions of law, shall, by rule, promulgate generally applicable standards for protection of the general environment from offsite releases from radioactive material in repositories.

In response, the EPA promulgated "40 CFR Part 191 - Environmental Radiation Protection Standards for the Management and Disposal of Spent Nuclear Fuel, High-Level and Transuranic Radioactive Wastes", on September $19,1985^{3}$. Subpart B of the 1985 disposal standards contained three long-term performance criteria for disposal, expressed in terms of cumulative release of radionuclides over 10,000 years (Containment Requirements), dose over 1,000 years (Individual Protection Requirements), and radionuclide concentration in groundwater over 1,000 years (Groundwater Protection Requirements). Subpart B also required six "assurance" measures to provide additional confidence that the Containment Requirements would be met.

In 1987, Subpart B of 40 CFR Part 191 was vacated and remanded to the EPA by a Federal Court of Appeals ${ }^{14}$. The Court found that the EPA had neither reconciled the Individual Protection Requirements with Part $\mathrm{C}$ of the Safe Drinking Water Act, nor explained the divergence between the two sets of criteria. Furthermore, the EPA had not explained the basis for the 1,000-year performance criterion in the Individual Protection Requirements. The Court also found that the Groundwater Protection Requirements were promulgated without proper notice and comment. Following vacating 40 CFR Part 191, a modification to the 1981 C\&C committed the WIPP Project to proceed with compliance planning in line with the 1985 disposal standards until the revised standards were promulgated ${ }^{12}$.

The LWA of $1992^{1}$ reinstated the 1985 disposal standards, excluding the parts of the standards that were questioned by the Court (40 CFR $\S 191.15$, Individual Protection Requirements, and 40 CFR $\S 191.16$, Ground Water Protection Requirements). As outlined in Sect. 1, the LWA required the EPA to promulgate disposal standards and 
specific criteria to apply these standards to the WIPP, and to evaluate the WIPP compliance application. Thus, the DOE ceased to be self-regulating.

On December 20, 1993, the EPA promulgated 40 CFR Part 191 disposal standards that corrected deficiencies associated with the 1985 Individual and Groundwater Protection Requirements ${ }^{4}$. In this revised rule, the time period for the Individual Protection Requirements performance criterion was increased to 10,000 years, consistent with the timescale for the Containment Requirements. The Groundwater Protection Requirements were made consistent with the Safe Drinking Water Act and moved from $\S 191.16$ of Subpart B to a new Subpart C entitled "Environmental Standards for Ground-Water Protection".

To develop the mandated criteria to apply the 40 CFR Part 191 disposal standards to the WIPP, the EPA published an Advanced Notice of Proposed Rulemaking (ANPR) in February 1993 (58 FR 8029), soliciting public comment on the development of the 40 CFR Part 194 rule. The EPA undertook several further rounds of public comment on its proposed rule, including release of a preliminary draft in January 1994, and publication of a notice of the proposed rule on January 30, 1995 (60 FR 5766). The EPA published its Final Rule, "40 CFR 194 - Criteria for the Certification and Recertification of the Waste Isolation Pilot Plant's Compliance with the 40 CFR Part 191 Disposal Regulations", on February 9, 1996. The EPA also published a Background Information Document ${ }^{15}$ and Response to Comments Document ${ }^{16}$ that described how the EPA had arrived at the criteria in the rule and addressed the comments it had received during the rulemaking process. In March 1996, the EPA issued Compliance Application Guidance $(\mathrm{CAG})^{17}$ for 40 CFR Part 194 to assist the DOE in the preparation of the WIPP CCA, and to assist the EPA in its compliance review.

Subpart A of 40 CFR Part 194 establishes general provisions related to the final rule, and Subpart B specifies the requirements for the format and content of compliance applications. Subpart C of 40 CFR Part 194 establishes the WIPP-specific criteria that apply to PAs and compliance assessments used to demonstrate compliance with the numerical disposal standards in 40 CFR Part 191. In addition, Subpart C implements the six assurance requirements of 40 CFR $\S 191.14$, and also establishes seven general criteria at $\S 194.21$ through $\S 194.27$ that apply to all activities associated with the WIPP CCA.

\section{HISTORICAL DEVELOPMENT OF THE WIPP PA}

The DOE's general framework for the WIPP PA had been developed prior to promulgation of the 40 CFR Part 194 criteria. This section summarizes the historical development of the WIPP PA; a more detailed description is given in Ref 18. 
The first quantified assessment of the long-term performance of the WIPP site was performed for the Final Environment Impact Statement ${ }^{19}$ (FEIS), which was prepared to comply with the National Environmental Policy Act of 1969. During the 1980s, much was learned about the WIPP site through site characterization, facility construction, and underground testing activities. In 1990, the analyses in the FEIS were updated for the Final Supplement Environment Impact Statement ${ }^{20}$ (SEIS) . During the early 1990s, in anticipation of the promulgation of the revised 40 CFR Part 191, an annual series of preliminary WIPP PAs was conducted ${ }^{21,22,23}$. These PAs were based on the regulations contained in the 198540 CFR Part 191 disposal standards ${ }^{24,25}$. The first WIPP PAs were conducted before passage of the LWA and publication of 40 CFR Part 194. The promulgation of the 40 CFR Part 194 Final Rule and CAG publication occurred early in 1996, less than a year prior to DOE's submission of the CCA. The compliance criteria codified good practice for analysis, documentation, QA, and treatment of uncertainty, and established the PA approach in contentious areas (e.g., human intrusion), in order to help the EPA and the public make a thorough evaluation of the CCA. The criteria attempted to avoid prescribing specific design choices and technical decisions. Because the CCA PA represented the culmination of previous preliminary PAs, the DOE was able to respond rapidly to the new site-specific criteria in 40 CFR Part 194.

\section{EPA REQUIREMENT AND CRITERIA RELEVANT TO THE CCA WIPP PA AND DOE COMPLIANCE APPROACH}

This section outlines the roles of the EPA regulations and criteria as they relate to the WIPP CCA PA. First, the role of the generally-applicable disposal standards in 40 CFR Part 191 is described. Sect. 4.1 describes the disposal standards themselves and how they set the context for the PA. Sects. 4.2. and 4.3 describe how the disposal standards and implementing criteria defined the assessment format and period of performance, respectively. Second, the criteria of 40 CFR Part 194 are described in terms of the key types of criterion that had a bearing on the CCA WIPP PA. Sect. 4.4 describes how the implementing criteria of 40 CFR 194 address the treatment of uncertainty in order to meet the "reasonable expectation" requirement of the disposal standards. Sect. 4.5 describes the role of the implementing criteria in defining the methodology for treating contentious issues, such as human intrusion. Sect. 4.6 describes the criteria that dictate documentation and QA of the PA models and data. Requirements for documentation and QA occur throughout 40 CFR 194 and underlie all other criteria; these requirements are discussed last to avoid repetition between sections. Third, Sect. 4.7 documents those 40 CFR Part 194 criteria that required quantitative analysis, but that did not have a direct effect on the CCA WIPP PA. To facilitate discussions of how different criteria were applied to different parts of the PA, a simplified flow chart of the PA process is shown in Fig. 2. 


\subsection{Disposal Standards and PA Context}

\subsubsection{CFR Part 191 Disposal Standards}

The numerical post-closure performance standards that must be addressed are set out in Subpart B of 40 CFR Part 191 as the Containment and Individual Protection Requirements and Subpart C of 40 CFR Part 191 as the Disposal Standards for the Groundwater Protection Requirements:

$\S 191.13$ Containment Requirements.

(a) Disposal systems for spent nuclear fuel or high-level or transuranic radioactive wastes shall be designed to provide a reasonable expectation, based upon performance assessments, that the cumulative releases of radionuclides to the accessible environment for 10,000 years after disposal from all significant processes and events that may affect the disposal system shall: (1) Have a likelihood of less than one chance in 10 of exceeding the quantities calculated according to Table 1 (Appendix A); and (2) Have a likelihood of less than one chance in 1,000 of exceeding ten times the quantities calculated according to Table 1 (Appendix A) .

(b) Performance assessments need not provide complete assurance that the requirements of $\$ 191.13$ (a) will be met. Because of the long time period involved and the nature of the events and processes of interest, there will inevitably be substantial uncertainties in projecting disposal system performance. Proof of the future performance of a disposal system is not to be had in the ordinary sense of the word in situations that deal with much shorter time frames. Instead, what is required is a reasonable expectation, on the basis of the record before the implementing agency, that compliance with $\S 191.13($ a) will be achieved.

$\S 191.15$ Individual Protection Requirements.

(a) Disposal systems for waste and any associated radioactive material shall be designed to provide a reasonable expectation that, for 10,000 years after disposal, undisturbed performance of the disposal system shall not cause the annual committed effective dose, received through all potential pathways from the disposal system, to any member of the public in the accessible environment, to exceed 15 millirems (150 microsieverts).

$\S 191.24$ Disposal Standards.

(a) Disposal systems. (1) General. Disposal systems for waste and any associated radioactive material shall be designed to provide a reasonable expectation that 10,000 years of undisturbed performance after disposal shall not cause the levels of radioactivity in any underground source of

\footnotetext{
${ }^{\mathrm{b}}$ Reference is to Table 1 in Appendix A of Ref. 3.
} 
drinking water, in the accessible environment, to exceed the limits specified in 40 CFR part 141 as they exist on January 19, 1994.

The accessible environment is defined ( $§ 191.12)$ to be "... (1) the atmosphere, (2) land surfaces, (3) surface waters, (4) oceans, and (5) all of the lithosphere that is beyond the controlled area". For the WIPP, the controlled area consists of the 16-section (41.4-square-kilometer) land area overlying the repository that was placed under jurisdiction of the DOE by the WIPP Land Withdrawal Act (as amended 1996). The requirements of $\S 191.15$ and $\S$ 191.24 apply only to undisturbed performance, which is defined by $\$ 191.12$ as "... the predicted behavior of a disposal system, including consideration of the uncertainties in predicted behavior, if the disposal system is not disrupted by human intrusion or the occurrence of unlikely natural events". Conversely, disturbed performance accounts for the possibility of unlikely natural events, human intrusion, and their consequences, and applies only to $\S 191.13$.

40 CFR $\S 191.14$ contains six assurance requirements designed to provide additional confidence that the disposal system will comply with the Containment Requirements of 40 CFR $\S 191.13$ : (1) use of active institutional controls; (2) monitoring of performance after disposal; (3) implementation of passive institutional controls; (4) use of both engineered and natural barriers; (5) avoidance of areas exploited for natural resources; and (6) feasibility of waste retrieval for a reasonable period of time after disposal. Design features introduced at the WIPP in order to meet the assurance requirements have had an effect on the conceptualization of the PA models. For example, the introduction of MgO backfill helps the WIPP comply with $\S 191.14(d)$, but also plays an important role in the PA. In addition, the implementation of active and passive institutional controls in accordance with $\S 191.14$ (a) and $\S 191.14$ (c) affects the likelihood of future human intrusion in the PA (see Sect. 4.5.5).

\subsubsection{Performance Assessment and Compliance Assessment}

40 CFR § 191.12 defines a PA as "an analysis that: (1) identifies the processes and events that might affect the disposal system; (2) examines the effects of these processes and events on the performance of the disposal system; and (3) estimates the cumulative releases of radionuclides, considering the associated uncertainties, caused by all significant processes and events. These estimates shall be incorporated into an overall probability distribution of cumulative release to the extent practicable."

40 CFR $\S 194.2$ defines a compliance assessment as meaning "... the analysis conducted to determine compliance with $\S 191.15$, and part 191, subpart C ...". 40 CFR Part 194 makes a clear distinction between the PA conducted to determine compliance with the Containment Requirements at $\S 191.13$ (disturbed performance), and the compliance assessments conducted to determine compliance with the Individual and Groundwater Protection Requirements at $\S$ 
191.15 and at $\S 191.24$ (undisturbed performance). In the $\mathrm{CCA}^{6}$, the disturbed performance $\mathrm{PA}$ and the undisturbed performance compliance assessments were discussed in separate chapters. However, the CCA compliance assessments mainly used a subset of the models and methodologies used for the CCA PA. Therefore, the remainder of this section focuses on the CCA WIPP PA, except where the compliance assessments adopted a significantly different approach.

\subsubsection{Role of the PA in the Decision-Making Process}

When combined with material to support reasonable PA models and data basis, PA results are a measure by which the compliance of the WIPP with the EPA's disposal standards in 40 CFR Part 191 is judged. PA is a means by which a "reasonable expectation" of compliance with the EPA's disposal standard is met. The concept of reasonable expectation is not explicitly defined in 40 CFR Parts 191 or 194, although the required statistical and probabilistic treatment of uncertainty is set out in 40 CFR Part 194. The following text from the EPA's 1998 certification rulemaking on the WIPP ${ }^{7}$ indicates that the DOE's approach of using a comprehensive and realistic probabilistic PA model, and adopting conservative assumptions where necessary, was an appropriate means of providing a reasonable expectation of compliance:

Based upon results of the CCA PA (as confirmed by the PAVT), EPA finds that the WIPP complies with the containment requirements by a comfortable margin, even when using more conservative parameter values that were changed significantly from those in the CCA PA. This modeling shows that the WIPP will contain waste safely under realistic scenarios, and even in many extreme cases. .....

Many [stakeholder ${ }^{c}$ ] comments were based on a philosophy that DOE should use an unrealistically conservative approach to the PA. .... The Agency found all of these suggestions to be inappropriate, either because they were unrealistic or because they required additional analysis when the change had already been demonstrated to have little or no impact on the PA results.

The Agency believes that the PA should be a reasonable assessment with some conservative assumptions built in, rather than an assessment comprised entirely of unrealistic assumptions and worst-case scenarios. The disposal regulations at 40 CFR Part 191 require the PA to show there is a reasonable expectation that cumulative releases will meet the containment requirements. This philosophy is reflected elsewhere in EPA's requirements, such as in the requirement for the mean $\left[\mathrm{CCDF}^{\mathrm{d}}\right]$ to comply with the containment requirement, rather than for every CCDF to comply. If unrealistically conservative assumptions were used in the PA, then results of the PA would not reflect reality and would not be a reasonable measure of the WIPP's capability to contain waste.

\footnotetext{
${ }^{\mathrm{c}}$ WIPP project stakeholders include interested organizations and members of the public.

${ }^{d}$ Conceptual Cumulative Distribution Function
} 


\subsection{Format of Assessment and Analytical Results}

The required assessment results for comparison with the regulations are determined by the standards in 40 CFR $\S$ 191.13(a), § 191.15(a), and $\S 191.24(a)$, as cumulative release, annual committed effective dose, and radionuclide concentration in groundwater, respectively. 40 CFR Part 194 provides additional criteria regarding the methodology for calculation of these results, and the format in which they should be presented.

\subsubsection{Format of Assessment Results}

Table 1 in Appendix A of 40 CFR Part 191 applies to the Containment Requirements at 40 CFR $\S 191.13(\mathrm{a})$, and specifies release limits to the accessible environment in curies per 1,000 metric tons of heavy metal (MTHM) for individual radionuclides. For a release to the accessible environment that involves a mix of radionuclides, the limits in 40 CFR Part 191 are used to determine a normalized release $(n R)$ of radionuclides for comparison with the Containment Requirements:

$$
n R=\sum_{i}\left(\frac{Q_{i}}{L_{i}}\right)\left(1 \times 10^{6} \frac{C_{i}}{C}\right)
$$

where $Q_{i}$ is the cumulative release in curies $\left(C_{i}\right)$ of radionuclide $i$ into the accessible environment during the 10,000 year period following closure of the repository, $L_{i}$ is the release limit in curies for radionuclide $i$ given in 40 CFR Part 191, and $C$ is the total amount of curies of alpha-emitting transuranic radionuclides with half-lives greater than 20 years to be emplaced in the repository.

For the compliance assessment results, the EPA criteria specify several calculational assumptions. For the annual committed effective dose, the protected individual shall be assumed to reside at the single geographic point on the surface of the accessible environment where that individual would be expected to receive the highest dose from radionuclide releases ( $\S 194.51$ ). All potential exposure pathways from the disposal system to individuals shall be considered and the individuals shall be assumed to consume two liters per day of drinking water from any underground source of drinking water in the accessible environment ( $\$ 194.52)$. Also, all underground sources of drinking water in the accessible environment that are expected to be affected by the disposal system over the regulatory time frame shall be considered ( $\$ 191.53)$. 
In performing the CCA compliance assessments, the DOE applied a bounding-analysis approach using unrealistic assumptions that resulted in over-estimation of potential doses and contaminant concentrations: (1) 40 CFR § 191.15 Individual Dose. Only 9 out of $300 \mathrm{CCA}$ undisturbed performance simulations led to non-zero (i.e., $>1 \times 10^{-18}$ curies/liter) calculated concentrations, all of which were still extremely low (from around $6 \times 10^{-18}$ up to a maximum of around $6 \times 10^{-12}$ curies per liter), and all of which were in the anhydrite interbeds within the Salado at the site boundary. All contaminants reaching the accessible environment were assumed to be directly available to a receptor. Brine derived from the anhydrite interbeds has total dissolved solids (TDS) concentrations of about 324,000 parts per million; this represents a concentration that could not be consumed by humans. For the bounding analysis, the calculation included the dilution of this brine by a factor of 32.4 to a TDS concentration of 10,000 parts per million, which is the upper limit for potable water; and (2) 40 CFR $\$ 191.24$ Groundwater Protection. The DOE assumed the presence of an underground source of drinking water (USDW ${ }^{\mathrm{e}}$ ) in close proximity to the WIPP land withdrawal area boundary, even though available data indicate that none exists near the boundary.

The 40 CFR Part 194 criteria do not specify a format for the compliance assessment results for 40 CFR § 191.15(a) and $\S 191.24(\mathrm{a})$. However, $40 \mathrm{CFR} \S 194.55$ (c) does require the calculation of several radiological measures using random samples from the entire range of values of each probability distribution developed to generate a range of: (1) estimated committed effective doses received from all pathways pursuant to $\S 194.51$ and $\S 194.52$; (2) estimated radionuclide concentrations in USDWs pursuant to $\$ 194.53$; and (3) estimated dose equivalent received from USDWs pursuant to $\S 194.52$ and $\S 194.53$. As described above, the DOE used a set of conservative bounding assumptions regarding exposure pathways to calculate maximum doses to individuals and maximum concentrations in USDWs. Because they were orders of magnitude within the compliance limits, only the maximum doses and concentrations were compared to the Individual and Groundwater Protection Requirements.

\subsubsection{Format of Analytical Results}

The format of the cumulative release results for 40 CFR $\S 191.13$ (a) is specified in more detail at 40 CFR $\$ 194.34(\mathrm{a})$, which requires the results to be assembled into "complementary, cumulative distribution functions" (CCDFs) that represent the probability of exceeding various levels of cumulative releases caused by all significant processes and events. The generation of multiple CCDFs is described in Ref. 26.

\footnotetext{
${ }^{\mathrm{e}}$ An Underground Source of Drinking Water is defined at 40 CFR $\S 191.22$ as "... an aquifer or its portion which: (1) Supplies any public water system; or (2) Contains a sufficient quantity of ground water to supply a public water system; and (i) Currently supplies drinking water for human consumption; or (ii) Contains fewer than 10,000 milligrams of total dissolved solids per liter".
} 


\subsection{Period of Performance}

The time period for both PA and compliance assessments is stated in 40 CFR Part 191 as 10,000 years. Comments were raised by stakeholders on drafts of both 40 CFR Parts 191 and 194, that the PA should model performance for 100,000 years or more. However, the EPA has maintained that times beyond 10,000 years are important, but that a disposal system capable of meeting the requirements for 10,000 years will continue to protect people and the environment well beyond 10,000 years $^{3}$. The WIPP is sited in a stable geological area and the $\mathrm{CCA}^{6}$ demonstrated that only negligible releases of radionuclides to the accessible environment might over 10,000 years. The four natural processes that have a progressive effect on the structure of the region and the hydrogeological properties of the units in the vicinity of the WIPP are regional uplift and tectonics, erosion, salt deformation, and dissolution. The rates of these processes are such that the WIPP repository is expected to maintain its integrity under undisturbed performance conditions well beyond 100,000 years.

\subsection{Treatment of Uncertainty}

Three principal types of uncertainty, related to the three different stages in the PA development process shown in Fig. 2, are important in PAs for radioactive waste disposal $\operatorname{sites}^{27}$ :

1. Scenario uncertainty. A scenario is a broad-brush description of the future evolution of the disposal system. Scenario uncertainty arises through different assumptions about the FEPs that may occur in the future and, hence, which FEPs and FEP interactions are included in a particular scenario.

2. Conceptual model uncertainty. Conceptual models are a set of qualitative assumptions used to describe a system or subsystem. At a minimum, these assumptions concern the geometry and dimensionality of the system, initial and boundary conditions, time dependence, and the nature of the relevant physical and chemical processes. Conceptual model uncertainty arises because there may be more than one way of describing a process or system within a particular context and in accordance with the data that are available.

3. Parameter uncertainty. Mathematical models of events and processes comprise a number of parameters and relationships, and solution of the mathematical model requires the assignment of particular values to the parameters. Parameter uncertainty arises where single values cannot be defensively derived or defined for these parameters. 
This section discusses how the 40 CFR Part 194 criteria address each of these types of uncertainty; see Refs. 26, 28, and 29 for additional discussion of the treatment of uncertainty in the CCA WIPP PA. The criteria that establish the statistical requirements for the comparison of the PA and compliance assessment results to the disposal standards are then described, along with the use of sensitivity analyses and peer reviews to further evaluate and reduce uncertainty in performance predictions.

\subsubsection{Scenario Uncertainty}

Although there are no specific references within 40 CFR Part 191 or 40 CFR Part 194 to scenario uncertainty, there is an implicit acknowledgement of scenario uncertainty in 40 CFR $\$ 194.32(\mathrm{e})$ and 40 CFR $\S 194.54(\mathrm{a})$, which require documentation of which FEPs have been included in assessment calculations and the basis on which other FEPs have been excluded.

The role of the EPA's regulations in defining scenario uncertainty by defining what and how FEPs are treated in the CCA WIPP PA is discussed in detail in Ref. 30. As stated earlier, 40 CFR $\S 191.13$ (a) requires PAs to consider "all significant processes and events that may affect the disposal system". 40 CFR $\S 194.32$ further defines the scope of the PA:

$\$ 194.32$ Scope of Performance Assessments.

(a) Performance assessments shall consider natural processes and events, mining, deep drilling, and shallow drilling that may affect the disposal system during the regulatory time frame.

(b) Assessments of mining effects may be limited to changes in the hydraulic conductivity of the hydrogeologic units of the disposal system from excavation mining for natural resources. Mining shall be assumed to occur with a one in 100 probability in each century of the regulatory time frame. Performance assessments shall assume that mineral deposits of those resources, similar in quality and type to those resources currently extracted from the Delaware Basin, will be completely removed from the controlled area during the century in which such mining is randomly calculated to occur. Complete removal of such mineral resources shall be assumed to occur only once during the regulatory time frame.

(c) Performance assessments shall include an analysis of the effects on the disposal system of any activities that occur in the vicinity of the disposal system prior to disposal and are expected to occur in the vicinity of the disposal system soon after disposal. Such activities shall include, but shall not be limited to, existing boreholes and the development of any existing leases that can be 
reasonably expected to be developed in the near future, including boreholes and leases that may be used for fluid injection activities.

(d) Performance assessments need not consider processes and events that have less than one chance in 10,000 of occurring over 10,000 years.

(e) Any compliance application(s) shall include information which: (1) Identifies all potential processes, events or sequences and combinations of processes and events that may occur during the regulatory time frame and may affect the disposal system; (2) Identifies the processes, events or sequences and combinations of processes and events included in performance assessments; and (3) Documents why any processes, events or sequences and combinations of processes and events identified pursuant to paragraph (e)(1) of this section were not included in performance assessment results provided in any compliance application.

Therefore, a comprehensive FEP list is required as a basis for the development of the WIPP PA (40 CFR $\S$ 194.32(e)(1)), but the only human activities that are required to be evaluated in developing scenarios are those currently occurring in the vicinity of the WIPP. The criteria for the scope of the compliance assessments ( $40 \mathrm{CFR} \S$ 194.54) are similar, but without the need to consider future drilling and mining other than that conducted on existing leases in the near future. The criteria and requirements for the treatment of future events and processes are also relevant to defining the scope of the PA, and are discussed in Sect. 4.5.1.

40 CFR $§ 194.32$ (d) allows the elimination of FEPs from the PA on the basis of low probability. Natural events for which there is no evidence of occurrence within the regional vicinity of the WIPP (the Delaware Basinf) were eliminated from the WIPP PA on this basis, as were waste- and repository-induced FEPs for which no mechanisms were identified that could result in their occurrence within the disposal system.

$40 \mathrm{CFR} \S 191.13$ (a) uses the term "significant" and, therefore, allows elimination of FEPs from PA calculations on the basis of insignificant consequence. Consequence can refer to effects on the site or to radiological consequence. On this basis, the DOE omitted FEPs from the CCA WIPP PA where there was a reasonable expectation that cumulative releases, as represented by the calculated CCDFs, would not be significantly changed by such omissions. In particular, the effects of some current practices as specified in 40 CFR $\S 194.32(\mathrm{c})$, such as brine extraction, fluid injection, and $\mathrm{CO}_{2}$ disposal, were eliminated from PA calculations on the basis of low consequence ${ }^{31}$.

\footnotetext{
${ }^{f}$ To avoid inconsistent interpretation, 40 CFR Part 194 defines the Delaware Basin as “... those surface and subsurface features which lie inside the boundary formed to the north, east and west of the disposal system by the innermost edge of the Capitan Reef, and formed, to the south, by a straight line drawn from the southeastern point of the Davis Mountains to the most southwestern point of the Glass Mountains."
} 
In accordance with 40 CFR $\S 194.32(\mathrm{e})$, the development of the WIPP FEP list, the elimination of FEPs, and the listing of FEPs that were retained for inclusion in the WIPP PA were documented in Appendix SCR of the CCA. FEPs that were eliminated were done so on the basis of their low probability of occurrence, their insignificant consequences, or as specified by the regulations (e.g., future states - the EPA specified that future human activities be represented as they are today such that futuristic activities would not need to be considered in scenario development).

\subsubsection{Conceptual Model Uncertainty}

There are no specific references within 40 CFR Part 191 or 40 CFR Part 194 to conceptual model uncertainty. The DOE used several criteria to determine which conceptual model to use in assessment calculations where plausible alternatives had been identified. These included the use of simplified models for computational efficiency where use of a more complex model would not affect calculated results, use of a model that is more conservative or accounts for a greater range of uncertainties, and use of established models where alternatives do not affect calculated results. In some cases, conceptual model uncertainty was accounted for by probabilistically sampling a flag to select one of two alternative models for each simulation (e.g., microbial degradation; see variable WMICFLG in Table 1 of Ref. 29). A tabulation of the alternative conceptual models considered in the WIPP PA, and how they were dealt with in the assessment, was submitted by the DOE to the EPA during review of the $\mathrm{CCA}^{32}$. The evaluation of the adequacy of the DOE's conceptual models was largely conducted by peer review (see Sect. 4.4.7). Further, as part of its rulemaking, the EPA required DOE to conduct a Performance Assessment Verification Test (PAVT) that evaluated uncertainties identified by the EPA in both conceptual models and parameter values ${ }^{33,34}$.

\subsubsection{Parameter Uncertainty}

There are extensive references to parameter uncertainty in 40 CFR Part 194 and associated documents. It is apparent from 40 CFR $\S 194.34$ (b) that the EPA expects the PA to use probability density functions (PDFs) or distributions to account for parameter uncertainty by stating that probability distributions for uncertain disposal system parameter values shall be developed and documented in any compliance application. This requires the DOE to use a probabilistic modeling technique, as set out at 40 CFR $\S 194.34$ (c), which states that computational techniques that draw random samples from across the entire range of the probability distributions shall be used in generating CCDFs and shall be documented in any compliance application. As a result of the above criteria, different types of parameter uncertainty are accounted for separately in the PA calculations for compliance with the Containment Requirements. A family of CCDFs allows a distinction to be made between stochastic uncertainty ${ }^{28}$, which controls the shape of a single CCDF, and subjective uncertainty ${ }^{29}$, which results in a distribution of CCDFs. 
Stochastic uncertainty is associated with future events such as human activities. No amount of additional study can provide additional quantitative information about this type of event, and these uncertainties must be defined using expert judgement. Distributions for parameters associated with stochastic uncertainty are sampled multiple times to generate a single CCDF. Subjective uncertainty is associated with data from site characterization and laboratory experiments. In theory, the acquisition of more data will reduce this type of uncertainty. Distributions for parameters associated with subjective uncertainty are sampled once for each CCDF. However, there is no explicit acknowledgement of this two-fold classification of uncertainty in the EPA's regulations, criteria, or supporting information. For more discussion of the classification, see Ref. 26.

\subsubsection{Comparison of PA CCDFs to the Containment Requirements}

The nature of the Containment Requirements in 40 CFR Part 191 makes a comparison between a single CCDF for cumulative release and the release limits a simple task, because both can be plotted on the same axes. If the CCDF lies to the left of the release limits, then the disposal system is in compliance. However, because the assessment calculations yield a distribution of CCDFs, the criteria at 40 CFR $\S 194.34$ (d) to (f) provide statistical tests for comparison of this distribution of CCDFs with the disposal standards:

(d) The number of CCDFs generated shall be large enough such that, at cumulative releases of 1 and 10, the maximum CCDF generated exceeds the 99th percentile of the population of CCDFs with at least a 0.95 probability. Values of cumulative release shall be calculated according to Note 6 of Table 1, Appendix A of Part 191 of this chapter.

(e) Any compliance application shall display the full range of CCDFs generated.

(f) Any compliance application shall provide information which demonstrates that there is at least a 95 percent level of statistical confidence that the mean of the population of CCDFs meets the containment requirements of $\S 191.13$ of this chapter.

The criterion at 40 CFR $\S 194.34$ (d) is intended to ensure that sufficient samples are generated to cover the full range of parameter values included in the PA, and hence that the calculated mean does represent a reliable estimate of disposal system performance. In the CCA, the DOE argued that a randomly selected CCDF has a 0.99 probability of lying below the 99th percentile of the population at cumulative releases of 1 and 10 , and that for $n$ randomly selected CCDFs, the probability of them all lying below the 99th percentile at cumulative releases of 1 and 10 is $0.99^{n}$. Conversely, the probability of at least one CCDF exceeding the 99th percentile at cumulative releases of 1 and 10 is $\left(1-0.99^{n}\right)$. In order to satisfy the criteria at 40 CFR $\S 194.34(d)$, the number of CCDFs must be such that $\left(1-0.99^{n}\right) \geq 0.95$, and hence $\mathrm{n} \geq 298$. The EPA accepted this analysis and agreed that the 300 CCDFs generated by the DOE for the CCA were sufficient to satisfy the criterion. 
In its Response to Comments on 40 CFR Part $194^{16}$, the EPA explained the basis at 40 CFR $\S 194.34$ (f) for requiring the mean of the population of CCDFs to meet the Containment Requirements, rather than the median or a higher percentile. The EPA believes that a measure of central tendency provides the best estimate of the disposal system's performance for the purpose of regulatory decision making. The EPA argued that the requirement for random sampling across the full range of parameter distributions ensures that the distribution of CCDFs will encompass the consequences of low-probability events or values. The use of the median, rather than the mean, would not take account of the extent to which these low-probability events or values skew the distribution of CCDFs, and a higher percentile would give them undue weight.

A determination of compliance should be based on a value determined from the entire distribution of possible CCDFs. However, the CCDFs presented in a PA are a subset of the infinite population of CCDFs that could be calculated. Confidence limits around the mean of the sample can be used to establish statistical confidence for the estimate of the mean of the entire population. The EPA requires the comparison with the Containment Requirements using the $95^{\text {th }}$ percent level of statistical confidence about the mean of the population, in order to provide the necessary assurance that the disposal system complies with the Containment Requirements

In the CCA, the DOE presented a plot of a mean CCDF with $95 \%$ confidence limits. The derivation of these is based on replicated sampling ${ }^{29,35}$. The use of Latin Hypercube Sampling (LHS), rather than random sampling, for generating CCDFs precluded the use of parametric uncertainty bounds. The technique used three replicate analyses ( 3 x 100 realizations) employing different LHS seeds. The required confidence limits were then determined from the standard error of the replicates and the appropriate percentile of the $t$-distribution.

\subsubsection{Comparison of Compliance Assessment Results with the Individual and Groundwater Protection Requirements}

Although no criteria are provided for the calculation or presentation of the compliance assessment results, the criteria at $\S 194.55$ do specify the number of samples and the use of confidence limits for comparison with the standards.

\section{$\S 194.55$ Results of Compliance Assessments.}

(d) The number of estimates generated pursuant to paragraph (c) of this section shall be large enough such that the maximum estimates of doses and concentrations generated exceed the 99th percentile of the population of estimates with at least a 0.95 probability. 
(e) Any compliance application shall display: (1) The full range of estimated radiation doses; and

(2) The full range of estimated radionuclide concentrations.

(f) Any compliance application shall document that there is at least a 95 percent level of statistical confidence that the mean and the median of the range of estimated radiation doses and the range of estimated radionuclide concentrations meet the requirements of $\S 191.15$ and part 191, subpart C of this chapter, respectively.

The requirement for demonstrating that a sufficient number of samples has been used to calculate doses and concentrations is similar to that for CCDFs at $\S 194.34$ (d). For compliance assessments, the criterion at $\S 194.55(\mathrm{f})$ differs from that at $\S 194.34(\mathrm{f})$ for the PA by specifying the use of confidence limits for both the mean and the median. There is no discussion by the EPA of the reasons for specifying both measures.

As stated in Sect. 4.2, the DOE used a set of conservative bounding assumptions regarding exposure pathways to demonstrate that the maximum doses to individuals and concentrations in USDWs were orders of magnitude below the Individual and Groundwater Protection Requirements. The DOE successfully argued (Section 8.1.4 of Ref. 6) that, if a conservatively calculated maximum complied with the disposal standards, the mean and median and their upper $95 \%$ confidence limit would also comply ${ }^{36}$.

\subsubsection{Sensitivity Analyses}

The EPA criteria do not explicitly require sensitivity analyses for the results of the WIPP PA, although a sensitivity analysis is required for the monitoring assurance criterion at $\S 194.42$ (see Sect. 4.7.2). Under the criteria to document the development of input parameters for the PA at $\S 194.23(\mathrm{c})(4)$ and 194.34(b), the DOE did conduct a sensitivity analysis of parameters used in the CCA WIPP PA ${ }^{37}$ (see also Appendix SA of Ref. 6). Furthermore, as part of its rulemaking, the EPA conducted its own sensitivity analyses to evaluate the significance of uncertainty in PA parameter values ${ }^{38}$.

\subsubsection{Peer Review}

Peer review is an important method of reducing qualitative uncertainty (Fig. 2). At 40 CFR $\S 194.27$ (a), the EPA required the DOE to carry out peer reviews in three areas, the first of which related to the conceptual models used in the CCA WIPP PA, and the second of which had a bearing on the PA modeling of waste-related FEPs: 
$\$ 194.27$ Peer Review.

(a) Any compliance application shall include documentation of peer review that has been conducted, in a manner required by this section, for: (1) Conceptual models selected and developed by the Department; (2) Waste characterization analyses as required in $\$ 194.24(\mathrm{~b})$; and (3) Engineered barrier evaluation as required in $\S 194.44$.

The DOE conducted these peer reviews in 1996, with further resolution of outstanding issues in $1997^{39,40,41}$. Furthermore, the DOE conducted peer reviews of "Engineered Systems Data", "Waste Form and Disposal Room Data"43, and "Natural Barriers Data" ${ }^{44}$ to qualify "historical" data for use in the CCA WIPP PA. Historical data are those data collected prior to implementation of the QA system required under 40 CFR Part 194, and the peer reviews were undertaken according to the QA criterion at 40 CFR $\S 194.22$ (b):

(b) Any compliance application shall include information which demonstrates that data and information collected prior to the implementation of the quality assurance program required pursuant to paragraph (a)(1) of this section have been qualified in accordance with an alternate methodology, approved by the Administrator or the Administrator's authorized representative, that employs one or more of the following methods: peer review, conducted in a manner that is compatible with NUREG-1297, "Peer Review for High-Level Nuclear Waste Repositories," published February 1988 (incorporation by reference as specified in $\$ 194.5$ ); corroborating data; confirmatory testing; or a quality assurance program that is equivalent in effect to ASME NQA-11989 edition, ASME NQA-2a-1990 addenda, part 2.7, to ASME NQA-2-1989 edition, and ASME NQA-3-1989 edition [excluding Section 2.1(b) and (c) and Section 17.1]. (Incorporation by reference as specified in $\$ 194.5$ ).

\subsection{Treatment of Future Events, Processes, and Human Intrusion Issues}

This section discusses how criteria in 40 CFR Part 194 prescribe the PA treatment of several contentious FEPs or issues, including the human activities of drilling and mining. The numerical implementation of these issues are described in Ref. 28. For the CCA WIPP PA, in terms of the PA process in Fig. 2, these criteria applied particularly during the development of conceptual and mathematical models and the parameterization of the PA database.

\subsubsection{Treatment of Future Events and Processes}


The 40 CFR $\S 194.32$ criteria defining the scope of the PA (Sect. 4.4.1) limit consideration of future human activities to current drilling and mining practices and are consistent with the future state assumptions set out in 40 CFR § 194.25:

$\S 194.25$ Future State Assumptions.

(a) Unless otherwise specified in this part or in the disposal regulations, performance assessments and compliance assessments conducted pursuant the provisions of this part to demonstrate compliance with $\S 191.13, \S 191.15$ and part 191, subpart C shall assume that characteristics of the future remain what they are at the time the compliance application is prepared, provided that such characteristics are not related to hydrogeologic, geologic or climatic conditions.

(b) In considering future states pursuant to this section, the Department shall document in any compliance application, to the extent practicable, effects of potential future hydrogeologic, geologic and climatic conditions on the disposal system over the regulatory time frame. Such documentation shall be part of the activities undertaken pursuant to $\$ 194.14$, Content of compliance certification application; $§ 194.32$, Scope of performance assessments; and $\S 194.54$, Scope of compliance assessments.

(1) In considering the effects of hydrogeologic conditions on the disposal system, the Department shall document in any compliance application, to the extent practicable, the effects of potential changes to hydrogeologic conditions.

(2) In considering the effects of geologic conditions on the disposal system, the Department shall document in any compliance application, to the extent practicable, the effects of potential changes to geologic conditions, including, but not limited to: dissolution; near surface geomorphic features and processes; and related subsidence in the geologic units of the disposal system.

(3) In considering the effects of climatic conditions on the disposal system, the Department shall document in any compliance application, to the extent practicable, the effects of potential changes to future climate cycles of increased precipitation (as compared to present conditions).

The assumption of current practice (40 CFR $\S 194.25(\mathrm{a})$ ) is based on the EPA's wish to limit speculation and uncertainty in the PA. For example, in the Supplementary Information to 40 CFR Part $194^{5}$, the EPA states that:

The Agency recognizes the inherently conjectural nature of specifications on future states and wishes to minimize such speculation in compliance applications. The Agency has found no acceptable methodology that could make reliable predictions of the future state of society, science, languages or other characteristics of future mankind. The Agency does believe that established 
scientific methods could make plausible predictions regarding the future state of three classes of natural processes, namely geologic, hydrogeologic and climatic conditions.

To comply with $40 \mathrm{CFR} \S 194.25$ (b)(1) and (2) regarding changes to hydrogeological and geological conditions, the CCA WIPP PA probabilistically sampled from 100 transmissivity fields generated for the Culebra Dolomite overlying the repository (see variable CTRAN in Table 1 of Ref. 29). Other potential changes in geological conditions were eliminated from PA calculations on the basis of either low probability or low consequence ${ }^{30}$.

The potential effects of climate change (40 CFR $\S 194.25(\mathrm{c})$ ) were also captured through the modeling of the Culebra, by applying a probabilistically sampled recharge factor (the Climate Index) to scale up the transmissivity fields by a factor between 1 and 2.25 (see variable CULCLIM in Table 1 of Ref. 29). The maximum value for the Climate Index was derived through an analysis of past and potential future climate change ${ }^{45}$ and three-dimensional hydrogeological modeling of its potential effects ${ }^{46}$.

\subsubsection{Treatment of Mining}

In the vicinity of the WIPP site, economically-viable mining of two potassium salts from the McNutt Potash Zone in the Salado Formation is an ongoing activity ${ }^{47} .40 \mathrm{CFR} \S 194.32$ (b) and (c) (see Section 4.4.1) define how the effects of current and possible future mining should be treated in the PA. The EPA elaborates further on its conceptual model for the effects of mining in the Supplementary Information to 40 CFR Part $194^{5}$. The EPA states:

Some natural resources in the vicinity of WIPP can be extracted by mining. These natural resources lie within the geologic formations found at shallower depths than the tunnels and shafts of the repository and do not lie vertically above the repository. Were mining of these resources to occur, this could alter the hydrologic properties of overlying formations - including the most transmissive layer in the disposal system, the Culebra dolomite - so as to either increase or decrease groundwater travel times to the accessible environment. For the purposes of modeling these hydrologic properties, this change can be well represented by making corresponding changes in the values for the hydraulic conductivity. The Agency has conducted a review of the data and scientific literature discussing the effects mining can induce in the hydrologic properties of a formation. Based on its review of available information, the Agency expects that mining can, in some instances, increase the hydraulic conductivity of overlying formations by as much as a factor of 1,000, although smaller and even negligible changes can also be expected to occur. Thus, the final rule requires DOE to consider the effects of mining in performance assessments. In order to consider the effects of mining in performance assessments, the DOE may use the location-specific values of hydraulic conductivity, established for the different spatial locations within the Culebra 
dolomite, and treat them as sampled parameters varying between unchanged and increased 1,000-

fold relative to the value that would exist in the absence of mining.

From this text, it is apparent that the EPA concluded that there are no minerals vertically above the repository similar in quality and type to those currently being extracted elsewhere in the Delaware Basin. Furthermore, the effects of mining in terms of changes in hydraulic conductivity can be modeled as occurring only in the Culebra.

Consistent with 40 CFR $\$ 194.32(\mathrm{c})$, in the CCA WIPP PA, all economically mineable resources in the vicinity of the disposal system outside the controlled area were assumed to be extracted in the near future. The extent of mining assumed was based on an analysis of the map of existing leases, setbacks from existing boreholes, and the presence of ore in the lease ${ }^{48}$. Consideration of future mining within the controlled area was limited to mining at the locations of resources that are similar in quality and type to those currently extracted from the Delaware Basin. An angle of draw was used to translate the area mined in the Salado to the area affected in the overlying Culebra. In its Background Information Document for 40 CFR Part $194^{15}$, the EPA discussed the possible range in value of the angle of draw. The DOE used an angle of draw of $45^{\circ}$ to be consistent with the EPA's discussions and calculations.

For the area in the Culebra affected by mining, the effects were incorporated in the PA by multiplying the locationspecific Culebra transmissivity values by a randomly sampled factor (mining multiplier) between 1 and 1,000 (see variable CTRANSFM in Table 1 of Ref. 29). In accordance with 40 CFR $\S 194.32$ (b), to determine whether mining in the controlled area occurred in the future, the CCA WIPP PA used a Poisson model with a $10^{-4}$ probability of mining occurring in any year ${ }^{28}$. In accordance with 40 CFR $\S 194.32(\mathrm{~b})$, the occurrence of mining was limited to only once per 10,000 years, so multiple mining events were not modeled.

\subsubsection{Treatment of Drilling}

Consistent with 40 CFR $\S 194.32$ (Sect. 4.4.1), the possible effects of drilling activities associated with the extraction of economic resources in the vicinity of the disposal system were evaluated in developing the CCA WIPP PA. Further criteria concerning the consideration of future deep and shallow drilling in the PA are provided at 40 CFR § 194.33:

\$194.33 Consideration of Drilling Events in Performance Assessments.

(a) Performance assessments shall examine deep drilling and shallow drilling that may potentially affect the disposal system during the regulatory time frame. 
(b) The following assumptions and process shall be used in assessing the likelihood and consequences of drilling events, and the results of such process shall be documented in any compliance application:

(1) Inadvertent and intermittent intrusion by drilling for resources (other than those resources provided by the waste in the disposal system or engineered barriers designed to isolate such waste) is the most severe human intrusion scenario.

(2) In performance assessments, drilling events shall be assumed to occur in the Delaware Basin at random intervals in time and space during the regulatory time frame.

(3) The frequency of deep drilling shall be calculated in the following manner: (i) Identify deep drilling that has occurred for each resource in the Delaware Basin over the past 100 years prior to the time at which a compliance application is prepared. (ii) The total rate of deep drilling shall be the sum of the rates of deep drilling for each resource.

(4) The frequency of shallow drilling shall be calculated in the following manner: (i) Identify shallow drilling that has occurred for each resource in the Delaware Basin over the past 100 years prior to the time at which a compliance application is prepared. (ii) The total rate of shallow drilling shall be the sum of the rates of shallow drilling for each resource. (iii) In considering the historical rate of all shallow drilling, the Department may, if justified, consider only the historical rate of shallow drilling for resources of similar type and quality to those in the controlled area.

(c) Performance assessments shall document that in analyzing the consequences of drilling events, the Department assumed that: (1) Future drilling practices and technology will remain consistent with practices in the Delaware Basin at the time a compliance application is prepared. Such future drilling practices shall include, but shall not be limited to: the types and amounts of drilling fluids; borehole depths, diameters, and seals; and the fraction of such boreholes that are sealed by humans; and (2) Natural processes will degrade or otherwise affect the capability of boreholes to transmit fluids over the regulatory time frame.

(d) With respect to future drilling events, performance assessments need not analyze the effects of techniques used for resource recovery subsequent to the drilling of the borehole.

40 CFR § 194.33(a) allows human intrusion scenarios involving intentional intrusion into the WIPP excavation (e.g., to recover resources) to be eliminated from consideration in the PA. 40 CFR $\S 194.33$ (b) dictates the probability model to be used for drilling events. In accordance with 40 CFR \& 194.33(b)(2), the CCA WIPP PA used a Poisson model to represent future drilling events as random in time based on the historical drilling rate: 


$$
p(n \mid \Delta t, \lambda)=\frac{[\lambda(\Delta t)]^{n}}{n !} e^{-\lambda \Delta t}
$$

where $p$ is the probability that some number $n$, an integer, of drilling events will occur in a time interval $\Delta t$ given a drilling frequency $\lambda$ (see Ref. 28 for additional discussion). Oil and gas are the only known resources below the WIPP horizon (655 meters) that have been exploited in the Delaware Basin. However, some potash and sulfur exploration boreholes have been drilled in the Delaware Basin to depths in excess of 655 meters below the surface relative to where the drilling occurred. Thus, consistent with 40 CFR $\S 194.33(\mathrm{~b})(3)$, the future rate of deep drilling within the controlled area and throughout the Delaware Basin was based on the rates of historical drilling for oil, gas, potash and sulfur exploration, and oil and gas exploitation in the Delaware Basin (Appendix DEL of Ref. 6). WIPP site investigation boreholes were excluded from the analysis.

Shallow drilling associated with exploration and extraction of water, potash, sulfur, oil, and gas has taken place in the Delaware Basin over the past 100 years. However, of these resources, only water and potash are present at shallow depths (less than 655 meters below the surface) within the controlled area. Thus, consistent with 40 CFR § 194.33(b)(4), the CCA WIPP PA used the historical record of shallow drilling associated with water and potash exploitation in the Delaware Basin to determine the future rate of shallow drilling (Appendix DEL of Ref. 6).

Consistent with 40 CFR $\S 194.33(\mathrm{c})$, the modeling of future drilling practices in the CCA WIPP PA was based on current practices associated with the activities described above. Drilling was modeled in the CCA as standard rotary drilling with drilling muds. The drilling model parameters, such as drill bit diameter, were derived from surveys of current practice in the Delaware Basin. Other drilling techniques, such as air drilling, were eliminated from PA calculations because they are not current practice in the Delaware Basin ${ }^{49}$. Several stakeholders stated that air drilling was current practice. However, in its rulemaking ${ }^{7}$, the EPA illustrates how the DOE had appropriately applied the criterion at $40 \mathrm{CFR} \S 194.33$ :

Some commenters said that air drilling is already occurring in the Delaware Basin, and thus, should be considered in the PA. ... The Agency found that air drilling is not used more frequently in the Delaware Basin as a whole than in the New Mexico portion of the Basin. At the $95 \%$ statistical confidence level, EPA found that, at most, only $1.65 \%$ of all wells in the Delaware Basin may have been drilled with air. In those records examined, none of the wells were drilled through the salt-bearing geologic formation, as would be required to penetrate the WIPP. ... This additional information confirms the Agency's conclusion ... that air drilling is not a current practice in the Delaware Basin. In particular, air drilling through the salt section (where the waste is present) is not consistent with current drilling practices in the Delaware Basin. ... The EPA 
disagrees that the frequency of air drilling must be less than one in ten thousand wells in order for DOE to leave it out of the PA. Section 194.33(c)(1) requires DOE to look at "drilling practices at the time a compliance application is prepared." This requirement refers to typical industry practices in the Delaware Basin at the time a compliance application is prepared. ... It was not intended to apply to experimental procedures, emergency procedures, or conjectured future practices. The Agency finds it unrealistic to consider a specific deep drilling method to be current practice or typical of drilling in the Delaware Basin when it is used for only a small percentage of all wells in the Basin.

On the basis of 40 CFR $\S 194.33$ (d), the WIPP PA did not account for the effects of techniques used for resource extraction and recovery, such as pumping, secondary recovery or brine disposal that might be used subsequent to the drilling of a borehole in the future.

\subsubsection{Borehole Plugging}

Consistent with 40 CFR $\S 194.33$ (c), borehole plugging practices were accounted for in the WIPP PA based on a survey of current drilling practices in the Delaware $\operatorname{Basin}^{50}$. Six plug configurations were identified that were potentially relevant to future borehole abandonment practice at the WIPP. These six configurations were approximated in the CCA WIPP PA by three conceptual plugging patterns: a continuous concrete plug; a two-plug model; and a three-plug model ${ }^{28}$. The degradation of the borehole plugs by natural processes was also analyzed. In the two-plug and three-plug models, the steel casing that isolates water-bearing and brine-bearing units above the Salado was assumed to begin to degrade within decades after abandonment and to fail completely after 200 years. The concrete plug above the Salado was also assumed to fail after 200 years, as a result of chemical degradation by brine following failure of the casing. After the plug and casing have failed, the PA assumed that the borehole was filled by a silty-sand-like material containing degraded concrete, corrosion products, and material that sloughs into the hole from the walls. For the continuous plug model and for the concrete plugs below the WIPP horizon in the two-plug and three-plug models, where the chemical environment is less aggressive than above the Salado, the plug properties were kept constant for 10,000 years ${ }^{50}$.

\subsubsection{Institutional Controls}

The criteria implementing the assurance requirements related to active and passive institutional controls (AICs and PICs; 40 CFR $\S 194.41$ and $\S 194.43$, respectively) are prescriptive in the manner in which the controls can influence the CCA WIPP PA:

$\S 194.41$ Active Institutional Controls. 
(b) Performance assessments sha1l not consider any contributions from active institutional controls for more than 100 years after disposal.

\section{$\S 194.43$ Passive Institutional Controls.}

(c) The Administrator may allow the Department to assume passive institutional control credit, in the form of reduced likelihood of human intrusion, if the Department demonstrates in the compliance application that such credit is justified because the passive institutional controls are expected to endure and be understood by potential intruders for the time period approved by the Administrator. Such credit, or a smaller credit as determined by the Administrator, cannot be used for more than several hundred years and may decrease over time. In no case, however, shall passive institutional controls be assumed to eliminate the likelihood of human intrusion entirely.

40 CFR Part 194 requires any credit taken for AICs and PICs in the WIPP PA to be justified by a full description of the controls ( $\S 194.41(\mathrm{a})$ and $\S 194.43(\mathrm{a}))$ and an evaluation of their longevity and effectiveness $(\S 194.41(\mathrm{a})$ and $\S$ 194.43(b)).

The EPA's expectation with regard to PICs is set out in the Supplementary Information to 40 CFR Part 1945:

In adopting the assurance requirements in 40 CFR 191, EPA expressly limited the credit for active institutional controls. EPA prohibited performance assessments from considering any contributions from active institutional controls for more than 100 years after disposal. See 40 CFR 191.14(a). EPA declined to similarly limit the effect of PICs in reducing the likelihood of human intrusion. 50 Fed. Reg. 38080. By contrast, EPA contemplated that PICs may discourage the likelihood of human intrusion for some period of time longer than active institutional controls. However, EPA indicated that it generally believed it was inappropriate to rely on PICs for extended periods of time. See 50 Fed. Reg. 38080. Based on the public comments and consistent with EPA's general view that it is inappropriate to rely on PICs for very long periods of time, EPA is constraining in the final rule the length of time that EPA could consider granting credit for PICs to several hundred years. EPA's decision about the actual efficacy of PICs proposed for the WIPP will be based on DOE's compliance application but may not exceed this limit.

Further, the degree to which PICs might reduce the future drilling rate can be reliably determined only through informed judgment. The Agency agrees with the NACEPT ${ }^{g}$ Committee that no rigorous and non-speculative method is available to determine the appropriate amount of credit for PICs. Thus, DOE's proposed reduction in the likelihood of human intrusion due to PICs would probably be conducted through an expert judgment process that considers the specific PICs to be

\footnotetext{
${ }^{\mathrm{g}}$ National Advisory Council for Environmental Policy and Technology
} 
implemented at the WIPP by DOE. The expert judgment performed specifically to determine the effect of PICs must satisfy the requirements of section 26 of today's action, on expert judgment.

The CCA WIPP PA took credit for $100 \%$ effectiveness of AICs for 100 years, i.e., no human intrusions were modeled for the first 100 years after closure. On the basis of an evaluation of the longevity and effectiveness of $\mathrm{PICs}^{51}$, the CCA WIPP PA assumed a 99\% effectiveness of PICs for the period between 100 and 700 years. This had the effect of reducing the likelihood of future human intrusion in the period 100-700 years after closure to one hundredth of its value after 700 years. However, the credit taken for PICs in the CCA was rejected by the EPA in its rulemaking ${ }^{7}$, because "... DOE did not use an expert judgment elicitation to derive the credit, as explicitly envisioned by the Agency." This rejection did not affect the compliance of the WIPP with the disposal standards, as further PA calculations conducted without taking credit for PICs showed little effect on the calculated releases ${ }^{7,3,34}$.

\subsubsection{Waste Loading}

The distribution of different waste types in the repository is potentially significant when calculating releases due to intrusion of the repository by a drill string. At 40 CFR $\S 194.24$ (d), the criterion prescribes that, in the absence of a waste-loading scheme, the PA assumes random emplacement of waste in the repository:

$\S 194.24$ Waste characterization.

(d) The Department shall include a waste loading scheme in any compliance application, or else performance assessments conducted pursuant to $§ 194.32$ and compliance assessments conducted pursuant to $\S 194.54$ shall assume random placement of waste in the disposal system.

For undisturbed performance calculations in the CCA WIPP PA, the waste inventory was assumed to be homogeneously distributed throughout the repository. For disturbed performance calculations, random sampling based on the repository design was used to determine if the drill bit intersected contact-handled (CH-TRU) or remote-handled (RH-TRU) waste ${ }^{28}$. For intersection of CH-TRU waste, the drill bit was assumed to penetrate three containers coming from three randomly-selected waste streams. Specifically, the waste streams penetrated were randomly sampled according to the proportion of the total waste inventory from each waste stream. For intersection of RH-TRU waste, the material removed by the drill bit was assumed to have the activity of a volume-averaged RHTRU waste stream.

\subsection{Documentation}


In addition to the documentation required as part of the PA development process, as indicated in the criteria discussed in Sects. 4.2 to 4.5 , criteria at $\S 194.22$ and $\S 194.23$ of 40 CFR Part 194 explicitly require documentation and QA of the models and data used in the PA. These criteria are summarized in Table 1 and the QA process is described in Ref. 52. In themselves, the criteria do not influence the conduct of the PA, but they do help to ensure traceability and consistency. All 40 CFR Part 194 documentation requirements were met in the CCA and in additional information submitted by the DOE at the request of the EPA. Note that the expert judgement process was not employed during development of the CCA WIPP PA and, therefore, the criteria concerning the documentation of expert judgement at $\S 194.26$ were not implemented by the DOE.

\subsection{Use of PA Models to Satisfy Other 40 CFR Part 194 Criteria}

The above sections have described the role of the PA and compliance assessments in demonstrating compliance with the EPA regulations, and the requirements placed on the PA by the regulations and criteria. In addition, quantitative assessment of disposal system performance is required to satisfy other criteria, including criteria for waste characterization at 40 CFR $\S 194.24$, for monitoring at $\S 194.42$, and for engineered barriers at $\S 194.44$, as discussed below. However, in these cases, a full PA is not generally required and the requirements on the CCA WIPP PA discussed in Sects. 4.1 to 4.6 do not necessarily apply.

\subsubsection{Waste Characterization}

The criteria at $40 \mathrm{CFR} \S 194.24$ (b) require an analysis of the influence of various waste characteristics and corresponding components on disposal system performance. 40 CFR $\S 194.24(\mathrm{c})$ goes on to require the setting of limits for significant waste components, and a demonstration that the WIPP complies with the disposal standards on the basis of these limits. A list of waste characteristics and components to be included in the analysis is given in the EPA criteria, and this list may have been influenced by preliminary WIPP PAs that showed such characteristics and components to be of potential significance to the predicted performance of the disposal system ${ }^{21,22,23}$. The preliminary PAs were not solely developed to measure WIPP's performance, but also to provide a development and refinement process for the PA as an adequate predictive tool for the WIPP. The CCA WIPP PA accounted for all of the waste characteristics specified in the regulations. The CCA specified waste acceptance criteria to meet upper or lower limits for metals, cellulosics, free water content in waste forms, and total curie content (for remote handled waste) in the repository. These limits are necessary to ensure that certain model assumptions and parameter values used in the CCA WIPP PA are valid and, therefore, that the results of the PA remain applicable.

\subsubsection{Monitoring}


A sensitivity analysis to determine significant disposal system parameters as candidates for monitoring is required as part of the implementation of the assurance requirements at 40 CFR § 194.42. The DOE developed monitoring plans according to whether: (1) they addressed significant disposal system parameters; (2) they addressed important disposal system concerns; (3) meaningful data could obtained in a short time period; (4) they could be conducted while preserving disposal system integrity; and (5) they are complementary with RCRA programs. On the basis of these criteria, ten monitoring parameters that may have a bearing on the WIPP PA calculations were identified (Section 7.2 of Ref. 6). To evaluate the first criterion of addressing significant disposal system parameters, the DOE compiled a list of parameters from the WIPP PA that: (1) represented one or more important aspects of a chemical or physical process or model; (2) represented subjective uncertainty; (3) represented stochastic uncertainty; or (4) proved to be moderately to highly sensitive in terms of modeling results in previous preliminary performance assessments. Each parameter in the list was assigned high, medium, and low significance values based on a sensitivity analysis of their potential effects on calculated releases (Appendix MON of Ref. 6).

\subsubsection{Engineered Barriers}

In the assurance requirements related to engineered barriers ( $40 \mathrm{CFR} \S 194.14(\mathrm{~d})$ and $40 \mathrm{CFR} \S 194.44$ ), a costbenefit analysis is required. In preparation for the CCA, an Engineered Alternatives Cost/Benefit Study was conducted $^{53}$. After identification and screening, 18 engineered alternatives (EAs) were identified for further analysis. Each EA was evaluated against factors given at $40 \mathrm{CFR} \S 194.44(\mathrm{c})$ using quantifiable performance measures that were identified for each factor. While some factors were characterized by a single performance measure, others required several performance measures to adequately describe the results. The performance measures were then organized and condensed to define a multi-element "impact vector" describing the complete analysis results for each EA for all factors. This analysis led to the selection of $\mathrm{MgO}$ backfill as an engineered barrier that could be beneficially introduced to improve long-term repository performance.

\section{CONCLUSIONS}

The EPA's general radioactive waste disposal standards at 40 CFR Part 191 establish the requirements for PA and compliance assessment, specify the assessment endpoints and timescales, and provide the basis for the use of PA results as a key measure by which the compliance is judged. In developing the compliance criteria at 40 CFR Part 194 to implement the generic 40 CFR Part 191 regulations specifically for the WIPP, the EPA created three key types of criterion in relation to the PA:

- $\quad$ Criteria that require or set the basis for rigorous analysis, documentation, and $Q A$ (e.g., $\S 194.22, \S$ $194.23, \S 194.32(\mathrm{e}), \S 194.54(\mathrm{a}))$. These criteria essentially ensure or codify good practice and promote 
traceability, thereby assisting the EPA and the public to evaluate the CCA. The criteria are not necessarily specific to the WIPP PA, and the DOE had already established a firm foundation in these areas prior to promulgation of 40 CFR Part 194.

Criteria to document and treat uncertainty (e.g., $\S 194.27, \S 194.34, \S 194.55$ ). These criteria are a particular subset of the first criteria type described above, and are again not necessarily specific to the WIPP PA. However, they are highilighted here as a separate type because they specifically apply to helping provide a reasonable expectation of compliance. The DOE approached the demand of reasonable expectation by developing and using a comprehensive and realistic probabilistic PA model. Conservative assumptions were also adopted where necessary; however, the intent was to avoid conservatism and include realism wherever possible.

- $\quad$ Criteria for establishing the PA approach in contentious areas (e.g., $\S 194.32(b), \S 194.33, \S 194.41$ (b), $\S$ 194.43(c)). These criteria are mostly site-specific in that they deal with technical issues related to the performance of the WIPP site and prescribe approaches that are particular to the characteristics of the WIPP site. In developing 40 CFR Part 194, considerable public consultation was undertaken concerning the issues covered by these criteria (e.g., mining, drilling, climate change). By deciding on what was reasonable and appropriate on the basis of this debate and by including the decision in the form of a required approach in 40 CFR Part 194, the EPA established a clear basis for reaching a decision on compliance, and accelerated the compliance determination process by resolving several contentious issues ahead of the DOE's preparation of the CCA.

Finally, the WIPP PA has a continuing role in meeting the requirements that will be demanded in future regulation of the WIPP, as part both of the modification and the recertification processes. The modification process covers requests by the DOE for significant changes to the CCA basis, while the recertification process covers the requirement at Section $8(f)(1)$ of the $L W A^{1,2}$ necessitating a recertification application to be submitted to the EPA at least once every five years during the operational lifetime of the WIPP. The DOE may request changes (operational efficiencies and enhancements) to the disposal system described in the CCA over the operational period of the WIPP. These planned changes may result from a number of initiatives, such as waste characterization process improvements. Furthermore, unplanned changes may arise, for example as a result of analysis of the WIPP monitoring programs. Changes will only receive regulatory approval after an impact assessment shows that the change will not lead to an unacceptable consequence. The DOE and its scientific advisor, Sandia National Laboratories, are committed to the continuing development of the technical basis underlying the WIPP PA, so as to ensure that the WIPP PA remains a defensible and credible tool for under-pinning such impact assessments. 
Continued use of the developing PA to evaluate performance of the WIPP will also provide further assurance and public confidence in the WIPP's compliance with the EPA's disposal standards. 


\section{REFERENCES}

1. WIPP Land Withdrawal Act, Public Law 102-579 (106 Stat. 4777), 1992.

2. WIPP Land Withdrawal Act as Amended, Public Law 104-201, Subtitle F (110 Stat. 2851), 1996.

3. U.S. EPA (Environmental Protection Agency), 40 CFR Part 191: Environmental Radiation Protection Standards for the Management and Disposal of Spent Nuclear Fuel, High-Level and Transuranic Radioactive Wastes; Final Rule. Federal Register, 1985, 50(182), 38066-38089.

4. U.S. EPA (Environmental Protection Agency), 40 CFR Part 191: Environmental Radiation Protection Standards for the Management and Disposal of Spent Nuclear Fuel, High-Level and Transuranic Radioactive Wastes; Final Rule, Federal Register, 1993, 58(242), 66398-66416.

5. U.S. EPA (Environmental Protection Agency), 40 CFR Part 194: Criteria for the Certification and ReCertification of the Waste Isolation Pilot Plant's Compliance with the 40 CFR Part 191 Disposal Regulations; Final Rule, Federal Register, 1996, 61, (28), 5224-5245.

6. U.S. DOE (Department of Energy), Title 40 CFR Part 191 Compliance Certification Application for the Waste Isolation Pilot Plant. DOE/CAO-1996-2184, U.S. Department of Energy, Carlsbad Area Office, Carlsbad, NM, 1996, Volumes I - XXI.

7. U.S. EPA (Environmental Protection Agency), 40 CFR Part 194: Criteria for the Certification and ReCertification of the Waste Isolation Pilot Plant's Compliance with the 40 CFR Part 191 Disposal Regulations: Certification Decision; Final Rule, Federal Register, 1998, 63(95), 27353-27406.

8. U.S. EPA (Environmental Protection Agency), Technical Support Document: Overview of Major Performance Assessment Issues. EPA Air Docket A-93-02, Item V-B-5, May 13, 1998.

9. National Academy of Sciences/National Research Council, Disposal of Radioactive Wastes on Land.. National Academy of Sciences - National Research Council Publication, Washington, D.C., 1957.

10. Powers, D.W., Lambert, S.J., Shaffer, S.-E., Hill, L.R. and Weart, W.D. (Eds.), Geological Characterization Report. Waste Isolation Pilot Plant, Southeastern New Mexico. SAND78-1596, Sandia National Laboratories, Albuquerque, NM, 1978.

11. Department of Energy National Security and Military Applications of Nuclear Energy Authorization Act of 1980, Public Law 96-164 (93 Stat. 1259, 1265), 1980.

12. U.S. DOE (Department of Energy), State of New Mexico vs. U. S. Department of Energy, Agreement for Consultation and Cooperation. Civil Action No. 81-0363 JB, July 1981 and supplements, revisions, and modifications dated December 1982, March 1983, November 1984, and March 1988.

13. Public Law 97-425. Nuclear Waste Policy Act of 1982 (NWPA), 96 Stat. 2201, 42 U.S.C. 10101 et seq., 1982. 
14. Natural Resources Defense Council, Inc. v. U.S. Environmental Protection Agency, et al., 824 Federal Reporter, $2 d$ Series 1258, 1987.

15. U.S. EPA (Environmental Protection Agency), Criteria for the Certification and Re-Certification of the Waste Isolation Pilot Plant's Compliance with the 40 CFR Part 191 Disposal Regulations. Background Information Document for 40 CFR Part 194. EPA 402-R-96-002, Office of Radiation and Indoor Air, Washington, D.C., 1996.

16. U.S. EPA (Environmental Protection Agency), Criteria for the Certification and Re-Certification of the Waste Isolation Pilot Plant's Compliance with the 40 CFR Part 191 Disposal Regulations. Response to Comments Document for 40 CFR Part 194. EPA 402-R-96-001, Office of Radiation and Indoor Air, Washington, D.C., 1996.

17. U.S. EPA (Environmental Protection Agency), Compliance Application Guidance for 40 CFR Part 194. EPA 402-R-95-014, Office of Radiation and Indoor Air, Washington, D.C., 1996.

18. Rechard, R.P., Historical Background on Performance Assessment for the Waste Isolation Pilot Plant. Reliability Engineering and System Safety (in this issue).

19. U.S. DOE (Department of Energy), Final Environmental Impact Statement, Waste Isolation Pilot Plant. DOE/EIS-0026, Vols. 1-2, U.S. Department of Energy, Assistant Secretary for Defense Programs, Washington, DC, 1980 .

20. U.S. DOE (Department of Energy), Final Supplement Environmental Impact Statement, Waste Isolation Pilot Plant. DOE/EIS-0026-FS, Vols. 1-13, U.S. Department of Energy, Office of Environmental Restoration and Waste Management, Washington, DC., 1990.

21. Bertram-Howery S.G., Marietta, M.G., Rechard R.P., Swift P.N., Anderson D.R., Baker B.L., Bean J.E., Beyeler W., Brinster K.F., Guzowski R.V., Helton J.C., McCurley R.D., Rudeen D.K., Schreiber J.D. and Vaughn P., Preliminary Comparison with 40 CFR Part 191, Subpart B for the Waste Isolation Pilot Plant, December 1990. SAND90-2347, Sandia National Laboratories, Albuquerque, NM, 1990.

22. WIPP Performance Assessment Division, Preliminary Comparison with 40 CFR Part 191, Subpart B for the Waste Isolation Pilot Plant, December 1991, SAND91-0893, Vols. 1-4, Sandia National Laboratories, Albuquerque, NM, 1991.

23. WIPP Performance Assessment Department, Preliminary Performance Assessment for the Waste Isolation Pilot Plant, December 1992. SAND92-0700, Vols. 1-5, Sandia National Laboratories, Albuquerque, NM, 1992.

24. Helton, J.C., Risk, Uncertainty in Risk, and the EPA Release Limits for Radioactive Waste Disposal. Nuclear Technology, 1993, 101(1), 18-39.

25. Helton, J.C., Anderson, D.R., Marietta, M.G. and Rechard, R.P., Performance Assessment for the Waste Isolation Pilot Plant: From Regulation to Calculation for 40 CFR 191.13. Operations Research, 1997, 45(2), $157-177$. 
26. Helton, J.C., Andersen, D.P., Basabilvazo, G., Jow, H.-J. and Marietta, M.G., Conceptual Structure of the 1996 Performance Assessment for the Waste Isolation Pilot Plant. Reliability Engineering and System Safety (in this issue).

27. NEA (Nuclear Energy Agency), Lessons Learnt from Ten Performance Assessment Studies. NEA/OECD Publication, Paris, 1997.

28. Helton, J.C., Davis, F.J. and Johnson, J.D., Characterization of Stochastic Uncertainty in the 1996 Performance Assessment for the Waste Isolation Pilot Plant. Reliability Engineering and System Safety (in this issue).

29. Helton, J.C., Martell, M.-A. and Tierney, M.S., Characterization of Subjective Uncertainty in the 1996 Performance Assessment for the Waste Isolation Pilot Plant. Reliability Engineering and System Safety (in this issue).

30. Galson, D.A., Swift, P.N., Anderson, D.R., Bennett, D.G., Crawford, M.B., Hicks, T.W., Wilmot, R.D. and Basabilvazo, G., Scenario Development for the Waste Isolation Pilot Plant Compliance Certification Application. Reliability Engineering and System Safety (in this issue).

31. Stoelzel, D.M. and Swift, P.N., Supplementary Analysis of the Effect of Salt Water Disposal and Waterflooding on the WIPP. EPA Air Docket A-93-02, Item II-G-25, June 25, 1997.

32. Dials, GE. LTR/DOE - CAO/G. Dials to EPA/R. Trovato - Third response package to EPA's letter of December 19, 1996 to DOE/A. Alm. EPA Air Docket A-93-02, Item II-I-07, February 7, 1997. Carlsbad, NM: U.S. Department of Energy, Carlsbad Area Office, 1997.

33. MacKinnon B, Freeze G. Summary of EPA-Mandated Performance Assessment Verification Test (Replicate 1) and Comparison with the Compliance Certification Application Calculations. EPA Air Docket A-93-02, Item II-G-26, July 25, 1997.

34. MacKinnon B, Freeze G, Jow H.-N. Supplemental Summary of EPA-Mandated Performance Assessment Verification Test (All Replicates) and Comparison with the Compliance Certification Application Calculations. EPA Air Docket A-93-02, Item II-G-28, August 8, 1997.

35. Iman, R.L., Statistical Methods for Including Uncertainties Associated with geologic Isolation of Radioactive Waste Which Allow for a Comparison with Licensing Criteria, Proceedings of the Symposium on Uncertainties Associated with the Regulation of the Geologic Disposal of High Level Radioactive Waste, Gatlinsburg, Tennessee, March 9-13, 1981, ed. D.C. Kocher, NUREG/CP-0022, CONF810372, Oak Ridge National Laboratory, Oak Ridge, Tennessee, 1982, 145-157.

36. U.S. EPA (Environmental Protection Agency), Technical Support Document for Section 194.55: Compliance Assessment Statistics. EPA Air Docket A-93-02, Item V-B-26, May 13, 1998. 
37. Helton, J.C., Bean, J.E., Berglund, J.W., Davis, F.J., Economy, K., Garner, J.W., Johnson, J.D., MacKinnon, R.J., Miller, J., O’Brien, D.G., Ramsay, J.L., Schreiber, J.D., Shinta, A., Smith, L.N., Stoelzel, D.M., Stockman, C. and Vaughn, P., Uncertainty and Sensitivity Analysis Results Obtained in the 1996 Performance Assessment for the Waste Isolation Pilot Plant. SAND98-0365, Sandia National Laboratories, Albuquerque, NM, 1998.

38. U.S. EPA (Environmental Protection Agency), Technical Support Document for Section 194.23: Sensitivity Analysis Report. EPA Air Docket A-93-02, Item V-B-13, May 13, 1998.

39. Wilson, C., Porter, D., Gibbons, J., Oswald, E., Sjoblom, G. and Caporuscio, F., Final Waste Isolation Pilot Plant Conceptual Models Peer Review Report (July 1996, Sandia WIPP Central Files WPO \#41805)). Waste Isolation Pilot Plant Conceptual Models Supplementary Peer Review Report (December 1996, Sandia WIPP Central Files WPO \#43153). Waste Isolation Pilot Plant Second Supplementary Conceptual Models Peer Review Report (January 1997, Sandia WIPP Central Files WPO \#44536), U.S. Department of Energy, Carlsbad Area Office, Office of Regulatory Compliance, Carlsbad, NM, 1996-1997.

40. Hrncir, D.C., Bresson, J.F., Robinson, P.J., Bonano, E.J., Waste Isolation Pilot Plant Waste Characterization Analysis Peer Review Report (July 1996, unpublished report included in the $\mathrm{CCA}^{6}$ as Appendix PEER, Section PEER.3.2); Waste Isolation Pilot Plant Supplementary Waste Characterization Analysis Peer Review Report (EPA Air Docket A-93-02, Item II-G-14), U.S. Department of Energy, Carlsbad Area Office, Carlsbad, NM, 1996-1997.

41. Bhada, R.K., Aimone-Martin, C.T., Duran, A., Kuhns, D.J., Lewis, C.R., Navratil, J.D., Rostami, J., Smith, D.M. and Wahi, K.K., Independent Peer Review of the U.S. Department of Energy. Waste Isolation Pilot Plant Engineered Alternatives Cost/Benefit Study Peer Review Report. July 1996, unpublished report included in the $\mathrm{CCA}^{6}$ as Appendix PEER, Section PEER.4.2, U.S. Department of Energy, Carlsbad Area Office, Carlsbad, NM, 1996.

42. Ross-Brown, D., Gibbons, B., Porter, D. and Schaltz, J., Waste Isolation Pilot Plant Engineered Systems Data Qualification Peer Review Report (July 1996, unpublished report included in the CCA ${ }^{6}$ as Appendix PEER, Section PEER.5.2); Waste Isolation Pilot Plant Supplementary Engineered Systems Data Qualification Peer Review Report (December 1996, EPA Air Docket A-93-02, Item II-G-13). U.S. Department of Energy, Carlsbad Area Office, Carlsbad, NM, 1996-1997.

43. Hrncir, D.C. and Knecht, R.D., Waste Isolation Pilot Plant Waste Form and Disposal Room Data Qualification Peer Review Report. July 1996, unpublished report included in the $\mathrm{CCA}^{6}$ as Appendix PEER, Section PEER.6.2, U.S. Department of Energy, Carlsbad Area Office, Carlsbad, NM, 1996.

44. Dunn, D.E., Caporuscio, F., Cloke, P.L., Sommers, D.A., Wilson, C. and Zhang, C-M., Waste Isolation Pilot Plant Natural Barriers Data Qualification Peer Review Report. August 1996, unpublished report included in the $\mathrm{CCA}^{6}$ as Appendix PEER, Section PEER.7.2, U.S. Department of Energy, Carlsbad Area Office, Carlsbad, NM, 1996. 
45. Swift, P.N., Long-Term Climate Variability at the Waste Isolation Pilot Plant, Southeastern New Mexico, USA. Environmental Management. SAND91-7055, Sandia National Laboratories, Albuquerque, NM, 1992.

46. Corbet, T.F. and Knupp, P.M, The Role of Regional Groundwater Flow in the Hydrogeology of the Culebra Member of the Rustler Formation at the Waste Isolation Pilot Plant (WIPP), Southeastern New Mexico. SAND96-2133, Sandia National Laboratories, Albuquerque, NM, 1996.

47. NMBMMR (New Mexico Bureau of Mines and Mineral Resources), Evaluation of Mineral Resources at the Waste Isolation Pilot Plant (WIPP) Site. Final Report, Vols. I-IV, 1995.

48. Larson, K.L., Mining Transmissivity Multiplier - Area to be mined. Unpublished Sandia Memorandum, April 25, 1996, Sandia WIPP Central Files (SWCF) WPO \#37455, included in the $C C A^{6}$ as Appendix MASS, Attachment 15-4, Sandia National Laboratories, Albuquerque, NM, 1996.

49. Westinghouse Waste Isolation Division, Current Drilling Practice in the Vicinity of the WIPP. EPA Air Docket A-93-02, Item IV-G-7, January 27, 1998.

50. Thompson, T.W., Coons, W.E., Krumhansl, J.L. and Hansen, F.D., Inadvertent Intrusion Borehole Permeability. Unpublished report, July 8, 1996, SWCF WPO \#39624, included in the $\mathrm{CCA}^{6}$ as Appendix MASS, Attachment 16-3, Sandia National Laboratories, Albuquerque, NM, 1996.

51. Trauth, K.M., Guzowski, R.V., Pflum, C.G. and Rodriguez, R.J., Effectiveness of Passive Institutional Controls in Reducing Inadvertent Human Intrusion into the Waste Isolation Pilot Plant for Use in Performance Assessments, Unpublished report, June 4, 1996, included in the $\mathrm{CCA}^{6}$ as Appendix EPIC, Sandia National Laboratories, Albuquerque, NM, 1996.

52. Froehlich, G.K., Ogden, H.C., and Byle, K.A. Software Quality Assurance in the 1996 Performance Assessment for the Waste Isolation Pilot Plant. Reliability Engineering and System Safety (in this issue).

53. U.S. DOE (Department of Energy), Engineered Alternatives Cost/Benefit Study; Final Report. DOE/WIPP 952135, Revision 0, U.S. Department of Energy, Carlsbad Area Office, Carlsbad, NM, 1995. 


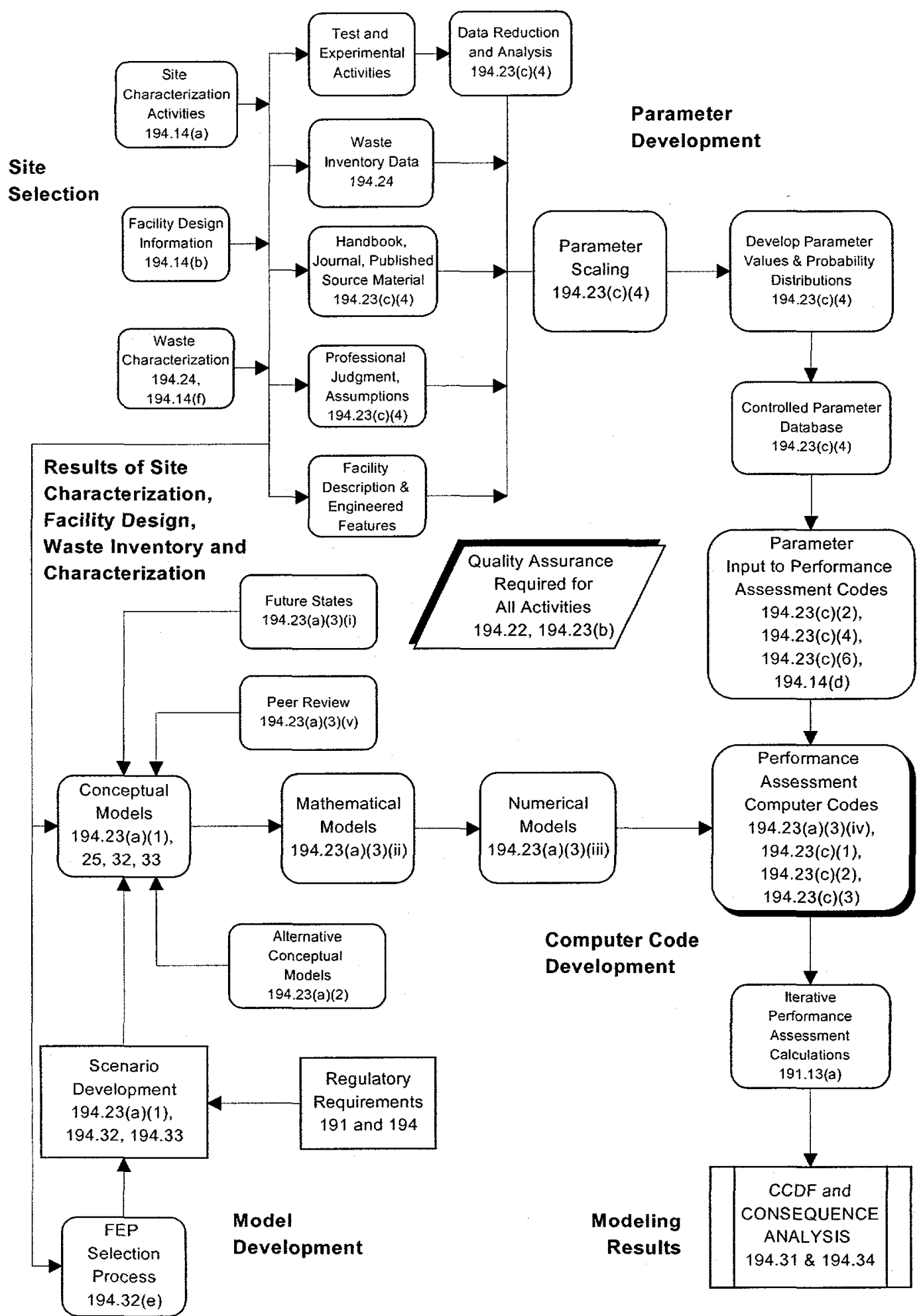

Fig. 1: EPA Regulations and PA Processes (from Ref. 8). 


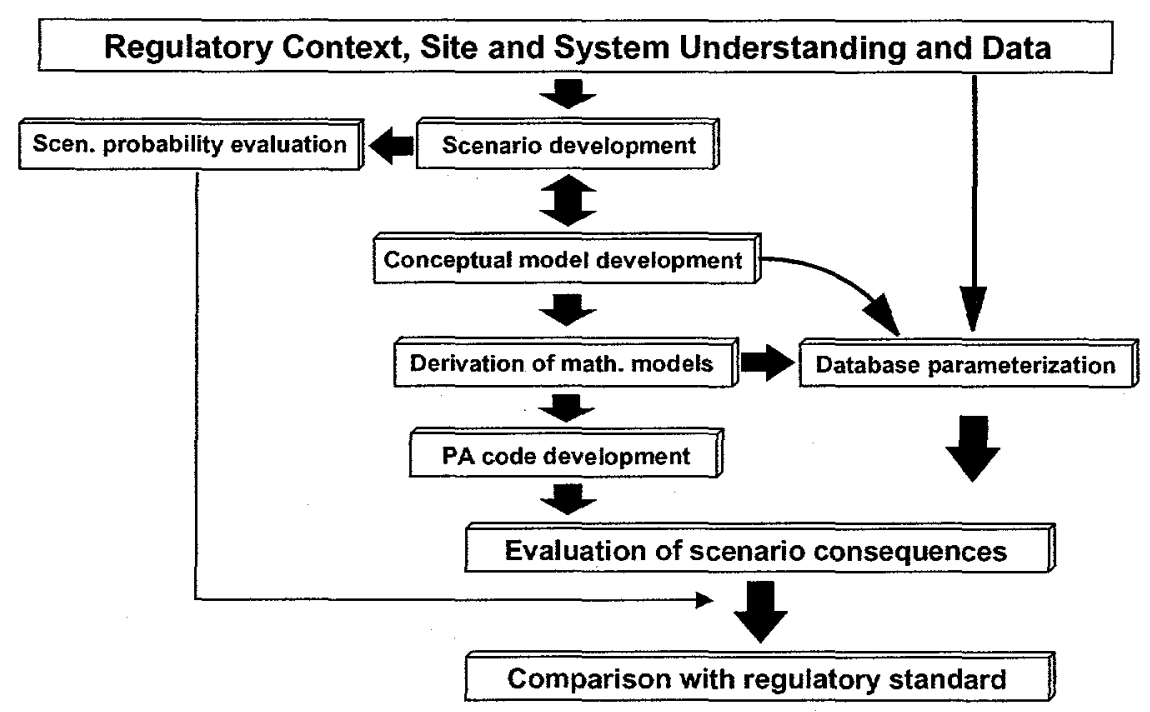

Fig. 2: Flowchart of the PA development process. 
Table 1: Documentation requirements for PA models and data at $\S 194.22$ and $\S 194.23$ in Subpart C of 40 CFR Part 194. Documentation requirements in criteria at $\S 194.25, \S 194.27, \S 194.32, \S 194.33, \S 194.34$, $\S 194.41, \S 194.43, \S 194.54$, and $\S 194.55$, have already been discussed in Sections 4.2 to 4.5 and are not included.

\begin{tabular}{|l|c|}
\hline \multicolumn{1}{|c|}{ Documentation Requirement } & EPA Criterion \\
\hline QA for computations, computer codes, models and methods used to & 40 CFR $\$ 194.22(\mathrm{a})$ \\
demonstrate compliance. QA for the collection of data and \\
information used to support the compliance application.
\end{tabular}

